\title{
Indoor climate analysis for urban mobility buses: a CFD model for the evaluation of thermal comfort
}

\author{
Roberto de Lieto Vollaro \\ Dept. Engineering of University of Rome 3, Via della Vasca Navale 79 - 00146 Rome, Italy \\ Email address: \\ roberto.delietovollaro@uniroma3.it (R.de Lieto Vollaro)
}

\section{To cite this article:}

Roberto de Lieto Vollaro. Indoor Climate Analysis for Urban Mobility Buses: a CFD Model for the Evaluation of thermal Comfort. International Journal of Environmental Protection and Policy. Vol. 1, No. 1, 2013, pp. 1-8. doi: 10.11648/j.ijepp.20130101.11

\begin{abstract}
The aim of this work is to analyze the indoor climate in city buses; the study was developed by numerical simulation and experimental validation carried out on the urban mobility buses of the city of Rome (Italy). Several factors have contributed to increase the concern about the comfort evaluation in vehicles and particularly in city buses. Due to the rising of the mobility needs, time that people spend in vehicles has grown substantially. The thermal environment in urban buses also varies greatly: passengers are exposed to local heating and/or cooling due to vertical temperature gradients, radiant asymmetry and local unexpected airflow. The interaction of the cabin thermal environment, created by the HVAC-system, the outdoor conditions as well as the occupants is rather complex. At the moment no standards exist for assessment and classification of the thermal environment quality in vehicles. To obtain some evidences, in order to enhance the indoor climate for a city bus and to improve occupants' comfort monitoring local temperature and air distribution around passengers, we have developed a mathematical model. The numerical model was implemented with Computational Fluid Dynamic software (CFD, Fluent Inc.): it permits the evaluation of the thermal and fluid-dynamic performances of the air conditioning system and diffusers' distribution. To gain a deeper understanding of the local climate comfort, the numerical simulation results were experimentally validated by several measurements inside the urban buses performed under real operative conditions during the summer season.The experimental results are in good agreement with the CFD evidences. This shows that the model developed can give reliable results to optimize and locally modify the air diffusers distribution inside cabin spaces. These evidences can help to improve the air conditioning distribution as a function of the obstructions' typical for a city bus vehicle and to reduce the draught risk related to the bus stop door apertures. One of the most important reasons of local temperature differences and unexpected air velocity gradients is due to the multi-door system apertures at each bus stop. This situation is particularly recurrent in a city area where an urban bus can afford several stops during his programmed route. For this reason it's important to get more information about this transient localized load for the climate conditions and about the time needed to reach again the steady conditions. To avoid or, at least, reduce this kind of problem it is proposed an air knife screened doors system bus. The thermo fluid dynamic results obtained show a significant improvement in the indoor climate comfort.
\end{abstract}

Keywords: Thermal Comfort, CFD model, Energy, Autobus

\section{Introduction}

Today people spend a long time in the public transport system. Due to the conditions of increasingly heavy traffic in large cities, public transport use is becoming more common. The idea of air conditioning in public transport arises from the need to improve the well being of the people who use it daily to move through the city. The internal temperature-humidity conditions are an important factor for the comfort and health of passengers, and also for the safety of drivers. For this reason, the automotive industry has developed systems for thermal comfort in vehicles more and more efficient in order to preserve the well being of the passengers and driver. The comfort issues for the environment inside the vehicle are extremely complex. Often inside the passengers' compartment are observed high gradients of velocity of air recirculation and temperature. Furthermore, the conditions of humidity and temperature are more compromised during the cooling and heating transient phase. The contribution of the solar radiations on the vehicles, especially in summer, should be also considered $[4,12,17]$.

The literature offers many studies that analyze the climate inside motor vehicles and there are several measure- 
ment systems to analyze speed and air temperature, and to validate the internal temperature and humidity conditions. Some researchers used to evaluate the thermal comfort in vehicles a model for calculation the expected average rating (EAV) and the percentage of dissatisfied (PPD). This method, tested in environments characterized by uniform and constant temperature conditions, is not valid for vehicles within which the parameters that affect the comfort of the users (radiant temperature, air velocity, etc.) are not uniform.

In fact, these parameters change frequently, according to the different occurrences in the external environment. The basic assumption on which the mathematical pattern is built, are the thermal balance of the human body and external uniform conditions. All these conditions does not occur on buses.

For this reason there were searched some mathematical models in the literature. It also takes into account the energy balance in transition conditions, i.e., to develop local comfort index for the human body in time.

For example, Taniguchi et al. (1992) developed a linear multiple regression model, which evaluates thermal sensation. The model assumes that passengers' thermal sensation in one vehicle depends not only on the superficial temperature of the skin of the face. It also depends on the derivative in correlation with the weather and its variations.

The Italian scenario is characterized by high technology in cars and airplanes transportation. This has brought to positive results in terms of passengers' comfort. However, the rail transport area does not have an adequate air conditioning technology, with serious inconvenience, as regards the thermal comfort of passengers. Public road transportation uses the technology from car industry, with its correlated difficulties. It is difficult to ensure a high comfort level of conditioning on public transportation (including buses and trains) in which the doors often open outwards allowing passengers to exit and enter the vehicle.

As regards the means of public transport on the road the air conditioning system is very simple. In general, for the heating system in winter, the most common method involves the use of engine cooling water even if they are also popular systems that involve the use of many electrical resistance. The summer cooling system is realized with a direct expansion structure, with compressor system directly connected to the engine of the bus.

The air distribution generally occurs through channels on the top of the bus. In the case of urban mobility buses, the air inlet into the environment takes place through the diffusion by terminals made in the ceiling with grid structures as well as in the air recovery system.

The aim of this study is to develop a numerical model, which when properly calibrated by the means of experimental measures, would allow the analysis of the effective air distribution. The development of the thermo fluid dynamic model should make possible to test new innovative solutions for the air conditioning system and air distributions like air screened doors.

\section{Numerical Analysis}

The mathematical model, implemented for the optimization of the air distribution system, inside the compartment of a bus, was built using CFD numerical analysis software (Fluent inc.).

The CFD, Computational Fluid Dynamics, software identifies the method which, through numerical algorithms, leads to the solution of the equations which modelizes the laminar, or a fluid's turbulent motion and of the related thermo-dynamic processes.

The modeling thermo-dynamic processes refer to the heat transmission in all its forms. With CFD is also possible to model the diffusion and the transportation of inert and reagent substances, the evaporation and the condensation and the homogeneous and heterogeneous combustion.

The formal refinement of the CFD calculation method has enabled the development as a tool of analysis in many engineering field.

The aim of our research was the characterization of the bus thermo fluid dynamic behavior. The environmental conditions of comfort are reached through different systems of mechanical ventilation.

The case study considered allows the evaluation of velocity field, which is both due to natural convention phenomena and imposed forced air flows. There have been also considered the influence on the ventilation system and on the thermo fluid dynamic characteristics of the "boundary" conditions as heat emerging from the engine, and others.

The implementation of a CFD code provides project validation, with low economic and time requirements. The comfort can thus be foreseen, building guidelines which are mostly useful in the early stages of the system designation, enhancing the reduction in energy consumption and improving people's wellbeing.

The numerical model of the thermo fluid dynamic phenomenon has been carried out on a continuous model. The governing equations for the indoor air system are the mass conservation equation and the Reynolds-averaged Navier-Stokes equations for three-dimensional fluid flow.

In the simulations, three mathematical representations are used to describe the air flow in the room. It was assumed that the flow is turbulent. I was used: the standard $\mathrm{k}-\varepsilon$ turbulence model. Details on Reynolds-averaging and the $\mathrm{k}-\varepsilon$ model are given by Gatski et al. [21,22].

In the standard $\mathrm{k}-\varepsilon$ model, model-dependent constants are determined empirically. Standard values for these constants are suggested by Jones and Launder [29]. The standard values for the constants have been found to work well for most situations, so alteration is generally unnecessary [19].

The standard $\mathrm{k}-\varepsilon$ model is based on the assumption of high Reynolds number flow; it was chosen this turbulence model because the application to the complex indoor air flows system as a bus cabin is justified.

The turbulence kinetic energy can be calculated based on 
the closure method, i.e. a turbulence model. Generally, the

TKE can be quantified by the mean of the turbulence normal stresses:

$$
\left.\left.\mathrm{K}=\frac{1}{2}\left(\left(\overline{u^{\prime} 1}\right)^{2}+\overline{\left(u^{\prime} 2\right.}\right)^{2}+\overline{\left(u^{\prime} 3\right.}\right)^{2}\right)
$$

TKE can be produced by fluid shear, friction or buoyancy, or through external forcing at low-frequency eddie scales(integral scale). Turbulence kinetic energy is then transferred down the turbulence energy cascade, and is dissipated by viscous forces at the Kolmogorov scale. This process of production, transport and dissipation can be expressed as:

$$
\frac{D k}{D t}+\nabla \cdot T^{\prime}=\mathrm{P}-\varepsilon
$$

where:

$\frac{D k}{D t}$ is the mean-flow material derivative of TKE;

$\nabla \cdot T$ ' is the turbulence transport of TKE;

$P$ is the production of TKE, and

$\varepsilon$ is the TKE dissipation.

The full form of the TKE equation is

$$
\begin{gathered}
\frac{\partial k}{\partial t}+\bar{u} \frac{\partial k}{\partial x j}=-\frac{1}{\rho_{0}} \frac{\partial \overline{k \bar{u}_{l} \bullet p}}{\partial x_{i}}-\frac{\partial \overline{k \bar{u}_{l}}}{\partial x_{j}}+v \frac{\partial^{2} k}{\partial x_{j}^{2}}-v \frac{\overline{\frac{\partial u_{l}^{\prime}}{\partial x_{j}}} \frac{\overline{u_{l}^{\prime}}}{\partial x_{j}}-}{\frac{g}{\rho_{0}} \overline{\rho_{1} u_{1}} \delta_{i 3}}
\end{gathered}
$$

$\frac{\partial \mathrm{k}}{\partial \mathrm{t}}$ Local derivative

$\overline{\mathrm{u}} \frac{\partial \mathrm{k}}{\partial \mathrm{xj}}$ Advection

$-\frac{1}{\rho_{0}} \frac{\partial \overline{\mathrm{k} \overline{\mathrm{u}}_{1} \cdot \mathrm{p}}}{\partial \mathrm{x}_{\mathrm{i}}}$ Pressure diffusion

$\frac{\partial \overline{\overline{\mathrm{k}}_{1}}}{\partial \mathrm{x}_{\mathrm{j}}} \quad$ Turbolent Transport T

$v \frac{\partial^{2} \mathrm{k}}{\partial \mathrm{x}_{\mathrm{j}}^{2}} \quad$ Molecular Viscous Transport

$\overline{\mathrm{u}_{\mathrm{l}}^{\prime} \mathrm{u}_{\mathrm{j}}^{\prime} \frac{\partial \overline{\mathrm{u}_{1}}}{\mathrm{x}_{\mathrm{j}}}}$ Production $\mathrm{P}$

$v \frac{\overline{\partial \mathrm{u}_{1}^{\prime}}}{\partial \mathrm{x}_{\mathrm{j}}} \frac{\overline{\mathrm{u}_{1}^{\prime}}}{\partial \mathrm{x}_{\mathrm{j}}}$ Dissipation $\varepsilon \mathrm{k}$

$\frac{\mathrm{g}}{\rho_{0}} \overline{\rho_{1} \mathrm{u}_{1}} \delta_{\mathrm{i} 3}$ Buoyancy flux b

By examining these phenomena, the turbulence kinetic energy budget for a particular flow can be found.[23]

In order to reach a solution, the values of field variables have to be known in an instant; furthermore, the conditions aimed at representing the interaction between the motion field and the surrounding environment have to be assessed under the calculative point of view.

The given conditions are: a normal velocity component, the tangential velocity component, the thermal flows of the integration domain.

The continuous formulation model is chosen; the discontinuation procedure draws on spatial derivatives of the field variables. This is done in each knot, with the algebraic value functions, the knot at issue and the adjacent knots. The discontinuation method chosen in this study is the finite element method.

Thus, a known procedure has been followed: the depen- dent variables in a turbulent situation are broken down in sums of average time value and fluctuation in comparison to that value. This kind of approach was firstly introduced by Reynolds for uncompressible flows and then, generalized by Favre to compressible flows.

The calculation procedure includes the solution grid's choice and of the numerical algorithms of integration. It also needs the definition of the convergence criteria and the adoption of a proper calculation instrument.

In particular, the numerical analysis of turbulent flows, requires the transformation of the equation variables' system (continuous mathematical model), into a system of algebraic relations (the discontinuous mathematical model).

In order to perform a simulation, it is necessary to generate a wide stitched grid which leads to a quick solution; afterwards, it is necessary to tighten the grid so as to increase the solution's resolution and accuracy. The tightening of the grid is necessary in the regions of the calculative domain where there are strong gradients of field variables. This is in order to avoid a less accurate result at a local and global level.

The motion equations applied for each knot, is a system of simultaneous equations in the field variables for all the knots of the grid; in our work an implicit algorithm is being employed.

A CFD code aimed at the analysis of air flows in closed environments and of the effects they lead to, must be able to foresee:

- the thermal comfort of the occupants;

- the efficiency and effectiveness of thermal energy distribution systems in the vehicle;

- the effectiveness of ventilation systems in removing or controlling the distribution of temperature and velocity variables.

To reach the objectives requested, it is necessary to identify the reference geometry of the functioning conditions of the single system as well as the thermal features of the surfaces that build the case in study.

In particular, the variation intervals of temperature and velocity variables, as well as the type and distribution of fluid flow inside and outside the vehicle, derive from the project optimization criteria.

\section{Actual Situation Analysis}

In this work it is analyzed also the worst situation for the passenger comfort: the thermo hygrometric changes, as transient temperature and air speed gradients, related to the bus stop with open doors. The opening and closing doors phase usually lasts for 20-30 seconds and substantially change the internal thermo fluid dynamic conditions by creating strong air speed and temperature gradients. The passenger comfort is lost especially in some areas of the vehicle compartment[16]. It is developed this study through different phases (i.e. five different stages). In the first stage, the mathematical method, for the numerical assessment in the thermo fluid dynamics field, was implemented for the 
urban mobility bus chosen for the study of comfort conditions. In the second phase, some experimental measures were applied inside buses. Such measures were then used to validate the implemented model[15].

Analyzing the different phases of bus working time (moving, traffic stop and at bus stops with open doors) it is also possible to evaluate the conditioning issue related to pollution. In summer time in large cities with high traffic densities, this becomes a crucial issue.

The shape of the compartment of the vehicle reproduces one common model of the urban mobility bus (Autobus) used in the city of Rome (Italy). The model was built starting from technical schemes of the real bus. Figures 1,2,3 and 4 show the temperature distribution at two analyzed heights to reveal and monitor the existence of possible unexpected temperature gradients.

The figures clearly show the distribution of temperature gradients in the bus passengers compartment. Two different height levels are presented: $1.25 \mathrm{~m}(4.1 \mathrm{ft})$ for seated passengers and $1.75 \mathrm{~m}(5.73 \mathrm{ft})$ for standing up passengers.

The thermo fluid dynamic model developed shows results that can be used for improvements in the conditioning system and in the air distribution grids to increase the passengers' comfort.

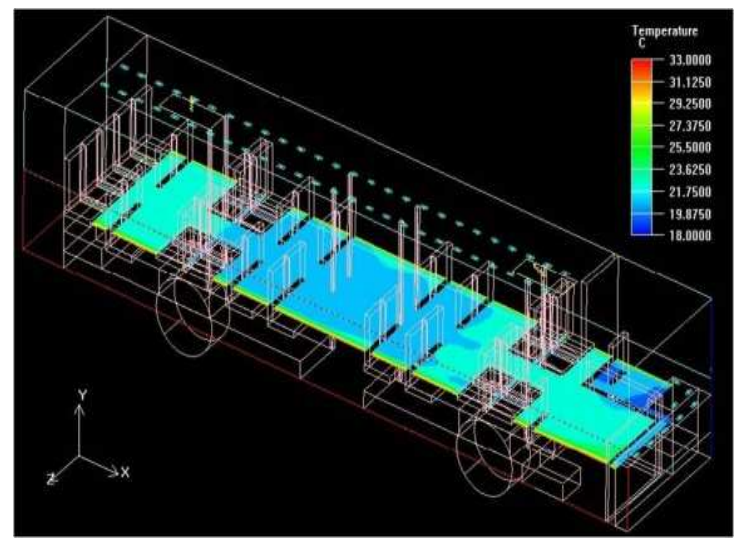

Figure 1. Moving phase, air conditioning system on. Temperature measurement at an height of 1,25 $\mathrm{m}$ (4.1 ft) above the floor.

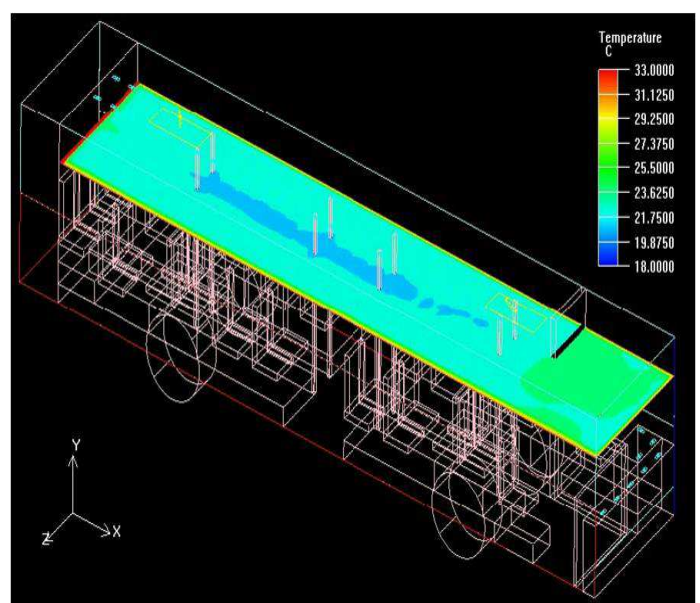

Figure 2. Moving phase, air conditioning system on. Temperature measurement at an height of $1,75 \mathrm{~m}(5.73 \mathrm{f})$ above the floor.

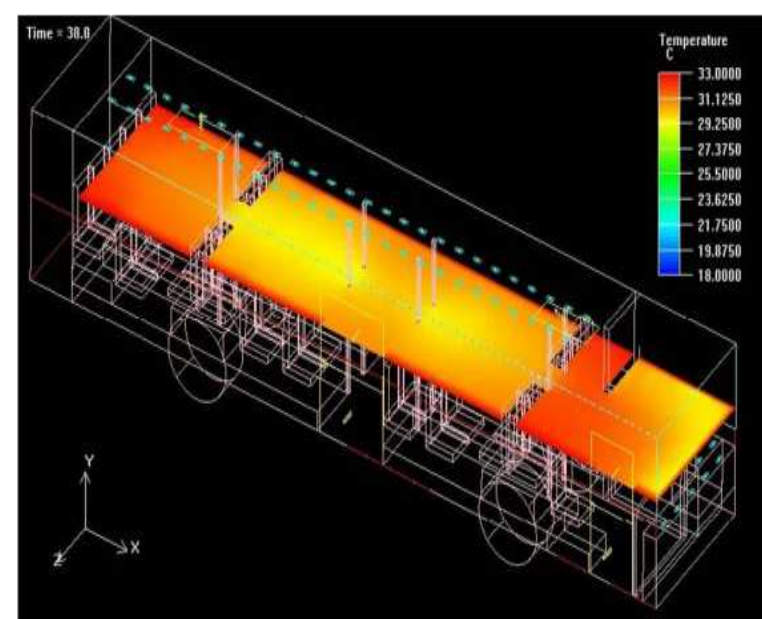

Figure 3. Traffic stop phase, air conditioning system on. Temperature measurement at an height of 1,75 $\mathrm{m}(5.73 \mathrm{ft})$ above the floor.

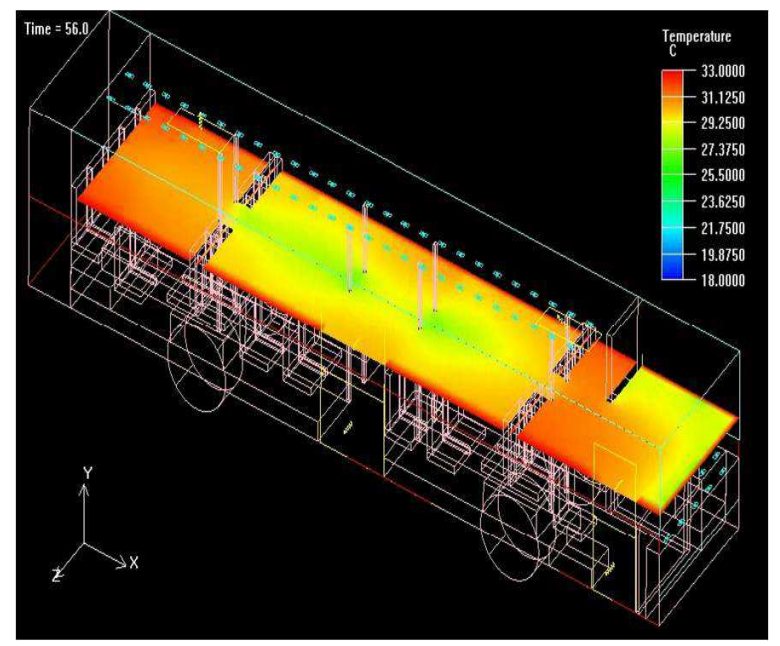

Figure 4. Traffic stop phase, air conditioning system on. Temperature measurement at an height of 1,25 $\mathrm{m}$ (4.1 ft) above the floor.

For the validation of the model it was executed some experimental measures inside the cabin of the bus, and the Tables 1 and 2 show some experimental results. Two representative conditions are chosen in the warmest hours of a summer day (July, 2012). It was analyzed the time intervals in which the outside temperature was nearly the temperature of $30^{\circ} \mathrm{C}\left(86^{\circ} \mathrm{F}\right)$. This is the value utilized in the simulation, to validate the numerical results obtained by CFD. In the third phase, the problems which lead to discomfort conditions inside buses have been identified.

The system's possible modifications have been studied in order to improve the climate conditions inside buses. In the fourth stage a numerical simulation has been performed using the system improvements identified. Finally, some interesting conclusions were reached. They would, however, have to be more developed in order to become commonly used on buses.

To validate our numerical model in tables $1,2,3$ and 4 it is presented some results obtained by experimental measurements in the urban mobility bus under analysis.

The first two tables show the values of temperature and 
air speed in some selected measurement points in two different situations: (i) moving vehicle with doors closed, and (ii) vehicle at bus stop with open doors. In both phases the air conditioning system is on $[13,14]$.

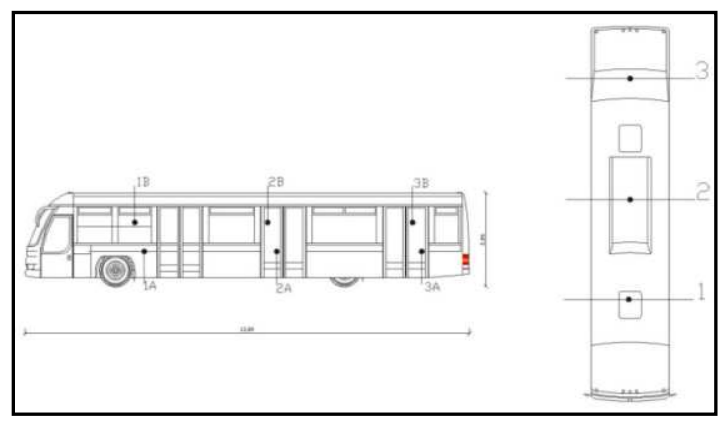

Figure 5. Scheme of the experimental measurement points.

Table 1. Vehicle at a bus stop with doors opened (1 minute).

\begin{tabular}{lllll}
\hline & $\mathbf{T}\left({ }^{\circ} \mathbf{C}\right)-\left({ }^{\circ} \mathbf{F}\right)$ & $\mathbf{V}(\mathbf{m} / \mathbf{s})-(\mathbf{m p h})$ & $\mathbf{T}$ & $\mathbf{V}$ \\
\hline point 1b & $27,2-80,9$ & $0,3-0,67$ & 1,1 & 0,79 \\
point 2b & $28,9-84$ & $0,3-0,67$ & 2 & 1,7 \\
point 3b & $27,6-81,6$ & $0,5-1,12$ & 1,3 & 1,3 \\
point 1a & $28,5-83,3$ & $0,9-2,01$ & 1,9 & 0,98 \\
point 2a & $27,5-81,5$ & $1,1-2,46$ & 1,94 & 2,7 \\
point 3a & $27,0-80,6$ & $1,3-2,9$ & 1,99 & 3,1 \\
\hline
\end{tabular}

Table 2. Moving Vehicle with doors closed.

\begin{tabular}{lllll}
\hline & $\mathbf{T}\left({ }^{\circ} \mathbf{C}\right)-\left({ }^{\circ} \mathbf{F}\right)$ & $\mathbf{V}(\mathbf{m} / \mathbf{s})-(\mathbf{m p h})$ & $\mathbf{T}$ & $\mathbf{V}$ \\
\hline point 1b & $25,1-77,18$ & $0,2-0,44$ & 1,17 & 2,1 \\
point 2b & $28,4-83,12$ & $0,3-0,67$ & 0,9 & 1,16 \\
point 3b & $27,2-80,96$ & $0,5-1,12$ & 1,23 & 1,57 \\
point 1a & $26,2-80,2$ & $0,7-1,56$ & 1,89 & 1,67 \\
point 2a & $26,1-78,9$ & $0,9-2,01$ & 0,94 & 1,12 \\
point 3a & $25,9-78,6$ & $1,1-2,46$ & 0,99 & 1,98 \\
\hline
\end{tabular}

The following tables 3 and 4 show the difference (\%) between the values measured experimentally and those obtained by the simulations. The differences are sufficiently lower in all the measurement point. These results validate our model as to be able to correctly describe the thermo fluid dynamics features of the buses.

Table 3. Difference (\%) between experimental and numerical values (doors closed).

\begin{tabular}{lll}
\hline & TEMP. GAP(\%) & VEL. GAP (\%) \\
\hline point 1b & 3 & 0,8 \\
point 2b & 3 & 0,8 \\
point 3b & 4 & 0,3 \\
point 1a & 3,5 & 0,3 \\
point 2a & 3 & 0,4 \\
point 3a & 5 & 0,65 \\
\hline
\end{tabular}

Table 4. Difference (\%) between experimental and numerical values (doors opened).

\begin{tabular}{lll}
\hline & TEMP. GAP(\%) & VEL. GAP $(\%)$ \\
\hline point $1 \mathrm{~b}$ & 1 & 0,1 \\
point 2b & 1 & 0,3 \\
point 3b & 2 & - \\
point 1a & 6 & 0,6 \\
point 2a & 2 & 0,1 \\
point 3a & 8 & 0,4 \\
\hline
\end{tabular}

\section{Air Knife Screened Doors}

To stabilize the passengers comfort also during the bus stop (open doors' phase) it was investigated the implementation of air screened doors (Figure 6). If properly sized and installed, the air screened doors generate, in correspondence of an opening, an invisible air screen. It is studied a system powered by a centrifugal blower unit, low-pressure and high-volume air production tool modeled specifically to blow-off all surface liquids and moisture that may be present.

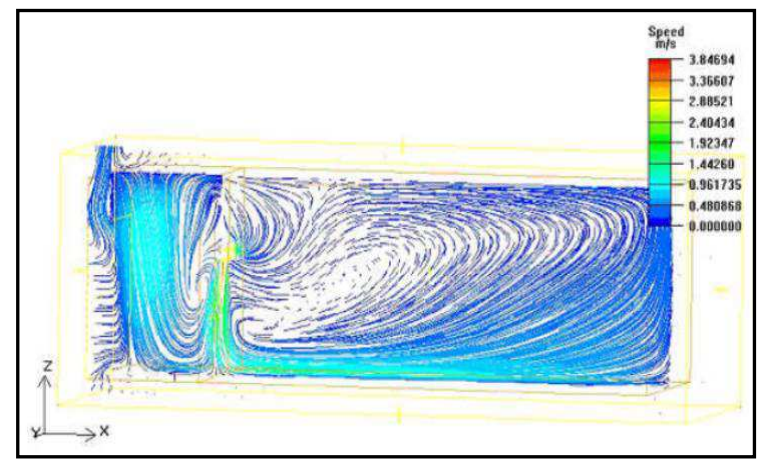

Figure 6. Fluid dynamic scheme of an air screened door.

This system guarantees low pressure operation, with the expansion ratio and turbulence of the air produced is reduced, clean air from the blower is both dry and oil free, safe centrifugal blowers operate on the principle of high velocity, low pressure air which presents no danger to passengers.

Air knives are typically used in manufacturing or as the first step in a recycling process to separate lighter or smaller particles from other components. They are a pressurized air plenum containing a continuous slot through which pressurized air exits in a laminar flow pattern. The exit air velocity then creates an impact air velocity onto the surface of whatever object the air is directed. This impact air velocity can range from a gentle breeze to greater than $40,000 \mathrm{ft} / \mathrm{min}$ to alter the surface of a product without mechanical contact.

It could be installed on the urban transport system as the autobus and it stops the air flows across the door and reduces the heat exchange between the inside and outside area of the conditioned bus. This innovative solution for buses air conditioning can guarantee to keep the environmental conditions to preserve the physical and psychologi- 
cal wellbeing of the occupants. Air Barrier creates a "virtual door" by re-circulating ambient air and forcing it across an opening to create up to a $70-90 \%$ seal in optimal condition. The seal separates the atmospheres on either side and stops the transfer of temperature, humidity, dust, odors and insects. With just a draught of air creating barrier, passengers can pass without obstruction.

Where doors are opening and closing frequently due to a high volume of traffic air barriers, it is also useful to reduce air conditioning energy costs by minimizing temperature loss across the door opening.

With reduced energy consumption typical installation provides a conservative Return On Investment of less than 2 years, and in some cases less than 1 year. Reduced demand on your heating or chilling systems reduces servicing costs, and increases their life expectancy.

Furthermore, the using the air barriers allows environmental protection from the trespassing fumes, particles and insects, keeping the room air clean.

The installation of the air barriers is relatively simple, and would not require structural changes of the vehicle; in fact does not require piping, wiring, structural changes, auxiliary electric system, and it could be integrated with the electric or pneumatic system of opening doors at the top of the doors, using the same electric cables.

This innovative usage in urban mobility buses transforms the air barrier from a simple separation element between the external and internal environments, to a system component of thermo hygrometric control of the internal space.

\subsection{Thermo Fluid Dynamic of the Air Knife Screened Door}

The air knife screened door proposal described above has been simulated with the model previously developed in order to evaluate the thermo fluid dynamic conditions also in the transient worst case of the bus stop; the thermal comfort benefits of improvements obtained by air screened door system that have also been studied by CFD $[1,2,3]$.

Some elements have been added to the bus structure models defined above. These elements satisfactorily simulate the air screened doors with the purpose of guaranteeing thermal insulation in situations such as the halting of the bus, which would otherwise be considered a real problem.

Once the technical thermo fluid dynamic specifications are known for the air screened doors currently on the market, it will be possible to test new solutions and analyze the benefits obtained.

Figures 7 and 8 clearly show how air screened door can preserve the steady state air distribution inside the compartment of the vehicle. In Figure 7, few seconds after the door opening, it clearly appears a strong thermal gradient which is the cause of discomfort for the passengers close to the doors. In figure 8 , the implementation of the air knife clearly shows how air barrier preserves the internal thermo-fluid dynamic uniformity.

The presence of the air screened doors can permit to obtain the same comfort level with a reduced indoor air tem- perature from $27-28^{\circ} \mathrm{C}\left(80.6-82.4^{\circ} \mathrm{F}\right)$ to $24-25^{\circ} \mathrm{C}(75.2-$ $77^{\circ} \mathrm{F}$ ). This permits to reduce the air conditioning energy consumption, and also reduce the exhaust gas air pollution.

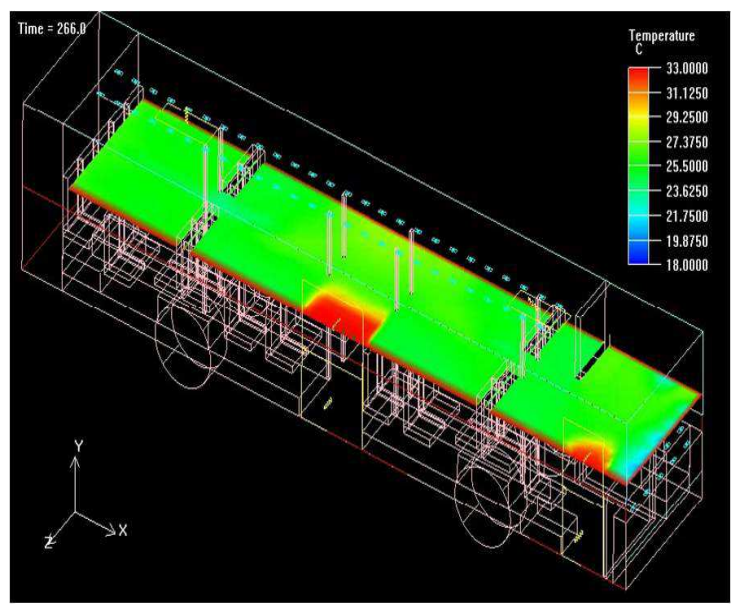

Figure 7. Bus stop phase - open doors, air conditioning system on.

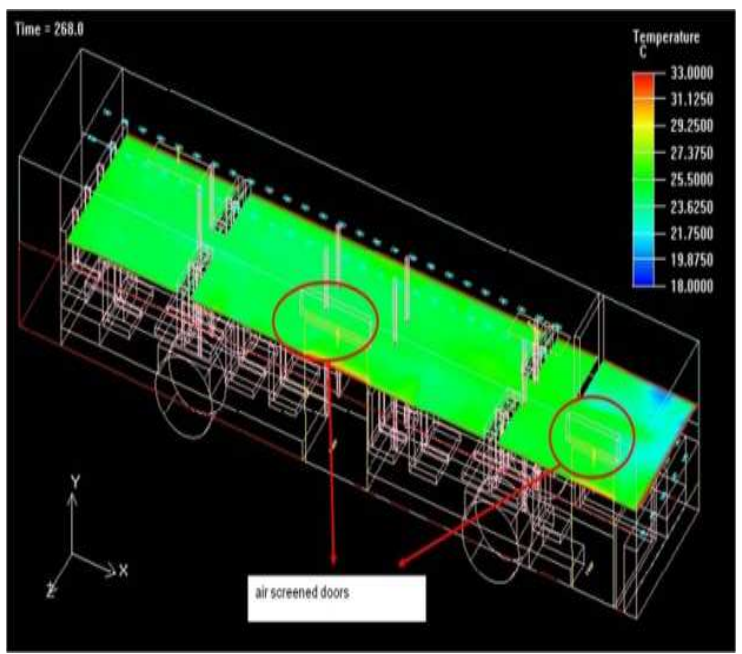

Figure 8. Bus stop phase - open doors, air conditioning system. Innovative air screened doors installed.

Actually, these temperature values are almost exactly those prescribed in standard EN 14750-1 (Air conditioning for urban and suburban rolling stock) for obtaining thermal comfort conditions inside vehicles falling into category A.

The installation of air screened door system, as already mentioned, is relatively simple, and would not require structural changes but could not be installed inside buses where at doors are present steps that can interrupt the return of airflow from the bus floor. Usually, the bus for public transportation usually avoids to introduce steps at the doors to facilitate the entrance of the person with disabilities.

\section{Conclusions}

This work has illustrated the results of a two year study on the comfort level inside urban mobility buses. The thermo hygrometric conditions inside passengers compartment has been analyzed. The existing common solutions of ceiling grid air distribution has been modelled by CFD 
software, and also validated by experimental measurements inside real buses of the city of Rome (Italy). It is presented the temperature and air speed distribution at two different heights: passengers sits an stand up. The numerical results obtained by CFD are in good agreements with experimental measurements (air temperature and speed). The model developed can be thus useful to predict the comfort results related with some new proposal in air conditioning, and grid distributions.

In this paper it was suggested and numerically modeling an innovative use of air screened doors. The worst situation for the passenger comfort is the thermo hygrometric changes, transient temperature and air speed gradients related to the bus stop with open doors. The passenger comfort is completely lost. To stabilize the passengers well being also during the bus stop (open doors phase) it is investigated the implementation of air screened doors.

The model built with CFD software, its validation with the experimental measures, and also the calibration of the grid pattern allowed us to analyze the air screened doors proposal to improve the thermal comfort also in the transient worst situation of the bus stop phase, particularly frequent in large area cities. These results authorize us to continue this research mainly through the experimental implementation of the air knife screened door proposed solution in a real urban mobility bus.

\section{Nomenclature}

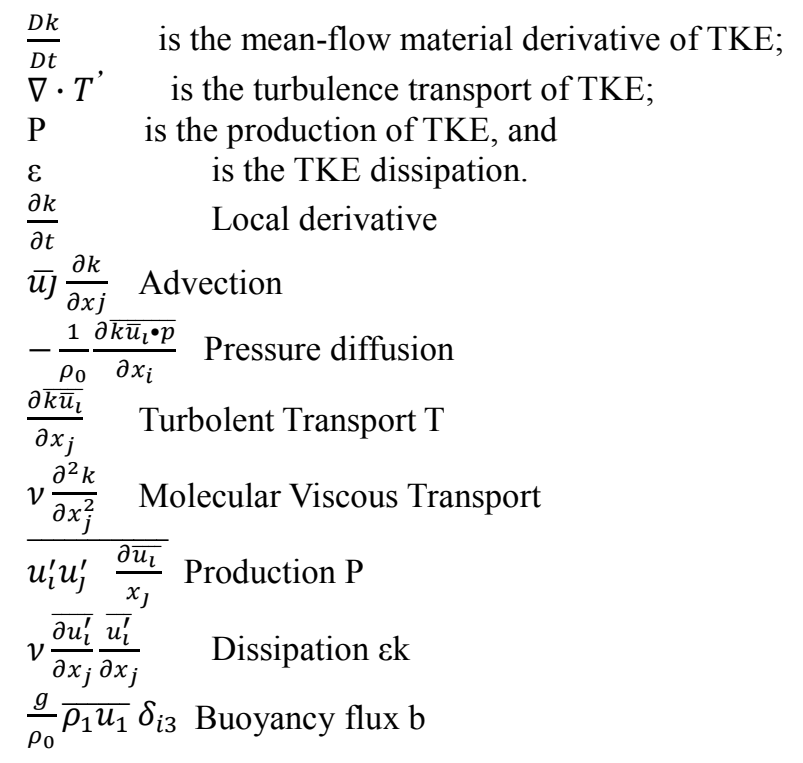

\section{References}

[1] Bruun H.H. 1995. Hot-wire anemometry. Principles and signal analysis. Oxford University Press, New York.

[2] Chen Q., Moser A. 1991. Simulation of a multiple nozzle diffuser. Proceedings of the 12th AIVC Conference, Vol.2, pp.1-14.

[3] De Lieto Vollaro R. 2011. Numerical analysis and measures for the evaluation of comfort inside buses used for public transport. In: Technical paper session 9, Montreal, July 1-2, pp.26

[4] Chow W.K., Wong L.T. 1997. Design of Air Diffusion Terminal Devices in Passenger Train Vehicle. Journal of Environmental Engineering, Vol.123, Issue 12, pp.1203-1207.

[5] Etheridge D., Sandberg M. 1996. Building Ventilation. Theory and Measurements. John Wiley \& Sons, Chichester, pp.391-446.

[6] Fanger P.O., Melikov A.K., Hanzawa H., Ring J. 1998. Air Turbulence and Sensation of Draught. Energy and Buildings, vol. 12 , pp. 21-39

[7] ISO Standard No.7730, 1997. Moderate thermal environments-determination of the PMV and PPD indices and specification of the conditions for thermal comfort. International Standards Organization (ISO)

[8] Hanzawa H., Melikow A. K., Fanger P.O. 1987. Airflow characteristics in the occupied zone of ventilated spaces. ASHRAE Transactions, Vol.93, pp.524-539.

[9] Patankar S.V. 1980. Numerical Heat transfer and fluid flow. Hemisphere Publishing Corporation, Washington.

[10] Thorshauge J. 1982. Air velocity fluctuations in the occupied zone of ventilated space. ASHRAE Transactions 88, pp.753-763.

[11] Taniguchi Y, Aoki H., Fujikake K., Tanaka H., Kitada M. 1992. Study on car air conditioning system controlled by car occupants' skin temperatures-part 1: Research on a method of quantitative evaluation of car occupants' thermal sensations by skin temperatures. SAE Paper Ser 920169, pp.13-19.

[12] Daniels R., Henser D. 2000. Valuation of environmental impacts of transport projects. Journal of transport economics and policy, Vol.34, issue 2, pp.189-214.

[13] UNI EN 27726. 1997. Thermal environments-Instruments and methods for measuring physical quantities.

[14] UNI EN 13182. 2002. Ventilation for buildings - Instrumentation requirements for air velocity measurements in ventilated spaces.

[15] Zhivov A.M., Zhang J.S., Christianson L.L. 1993. Characteristics of diffuser air jets and airflow in the occupied regions of mechanically ventilated rooms-a literature review. ASHRAE Transactions, Vol.99, issue 1, pp.1119-1127.

[16] EN 14750-1. 2006. Railway applications - Air conditioning for urban and suburban rolling stock - Part 1: Comfort parameters

[17] Khamis Mansour M., Musa Md Nor, Wan Hassan Mat Nawi, Saqr Khalid M. 2008. Development of novel control strategy for multiple circuit, roof top bus air conditioning system in hot humid countries. Energy Conversion and Management, Vol.49, issue 6, pp.1455-1468.

[18] Miyata Etsuji, Takeuchi Hirotsugu, Imazu Masataka 1996. Development of De-misting Techniques for Bus Air Conditioning - Dehumidification Control at Outside Temperature Below Freezing Point. JSAE Review, Vol.17, Issue 4, pp. 455-456.

[19] Eriksson P., Friberg O. 2000. Ride comfort optimization of a 
city bus - Structural and multidisciplinary optimization. Structural and Multidisciplinary Optimization Journal, Volume 20, Issue 1, pp 67-75

[20] De Lieto Vollaro R,, Grignaffini S., Vallati A. 2008. Numerical analysis and measures, for the evaluation of comfort inside buses used for public transportation. In: Urban Transport XIV: Urban Transport and the Environment in the 21st Century WIT Press Malta, September 1-3, 2008, pp763

[21] Posner J.D., Buchanan C.R., Dunn-Rankin D. 2003. Measurement and prediction of indoor air flow in a model room. Energy and Buildings, Vol.35, Issue 5, pp.515-526.
[22] Gatski T.B., Hussaini M.Y., Lumley J.L. 1996. Simulation and Modeling of Turbulent Flows, Oxford University Press, New York, USA.

[23] Baldocchi, D. (2005), Lecture 18, Wind and Turbulence, Part 1, Surface Boundary Layer: Theory and Principles , Ecosystem Science Division, Department of Environmental Science, Policy and Management, University of California, Berkeley, CA: USA. 